\section{THE FREQUENCY AND IMPACT OF PROCEDURAL DISTRACTIONS AND INTERRUPTIONS IN THE ADULT CARDIAC CATHETERISATION LABORATORY}

${ }^{1}$ Kalaivani Mahadevan, ${ }^{1}$ Elena Cowan*, ${ }^{2}$ Navneet Kalsi, ${ }^{1}$ Helena Bolam, ${ }^{1}$ Geraint Morton, ${ }^{1}$ Kaushik Guha, ${ }^{1}$ Peter Brennan, ${ }^{1}$ Paul Kalra. ${ }^{1}$ Portsmouth Hospitals NHS Trust; ${ }^{2}$ Hampshire Hospitals NHS Trust

\subsection{6/heartjnl-2019-BCS.52}

Purpose To understand factors contributing to disturbances during cardiac procedures, including frequency and nature of distractions, along with assessment of operator 'work-load' through NASA Task-load indices.

Methods A single centre prospective observational study was conducted on 194 consecutive patients undergoing cardiac procedures in 3 adult cardiac CL's over a period of 4 weeks. A distraction pro-forma was completed for each case by CL team members (predominantly physiologists), documenting procedural logistics and referring both to the level of risk of the procedure at that time (table 1) and frequency, nature and magnitude of each distraction/interruption (table 2). The primary operator completed a NASA Task-load questionnaire rating parameters to include mental and physical effort, level of frustration, time-urgency, and overall effort and performance on a scale of $1-21$.

Results 264 distractions occurred in 106 procedures $(55 \%$ of total); $80 \%$ were not relevant to the case being undertaken; $13 \%$ were due to emergencies occurring in the 'Hot- Lab' predominantly to discuss potential ST-elevation myocardial infarction requiring emergency angioplasty. Frequency of distractions per case ranged from 1 to 16 , with an average of $2.5 ; 16 \%(n=43)$ of these were documented to occur during high-risk stages (categories 3 or 4 ) of the procedure. Operator rating of NASA task-load parameters demonstrated higher levels of 'mental' and 'physical' workload and 'effort' when distractions occurred (figure 1).

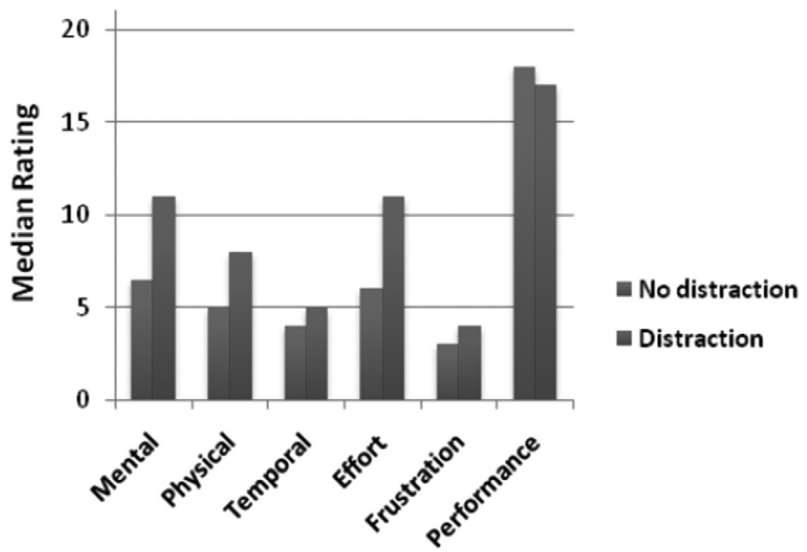

NASA Taskload parameter

Abstract 54 Figure 1

Conclusion In this first description of human factors in the adult cardiac CL we have shown that less than half of all procedures are completed without interruption/distraction. The vast majority of these are unnecessary and without relation to the case or list. We therefore propose the introduction of a 'sterile cockpit' environment in the CL, as has been adapted from the aviation industry within surgical operating theatres, to minimise

Abstract 54 Table 1 Procedural risk category

\begin{tabular}{|c|c|c|c|c|}
\hline & Risk category 1 & Risk category 2 & Risk category 3 & Risk category 4 \\
\hline Primary PCl & Vascular access & $\begin{array}{l}\text { Catheter exchange } \\
\text { Contrast delivery }\end{array}$ & $\begin{array}{l}\text { Critical time to } \\
\text { open artery } \\
\text { Balloon inflation } \\
\text { and stent delivery }\end{array}$ & $\begin{array}{l}\text { Cardiac arrest } \\
\text { Pericardial } \\
\text { effusion/tamponade } \\
\text { Life threatening bleed }\end{array}$ \\
\hline Elective PCl & Vascular access & $\begin{array}{l}\text { Catheter exchange } \\
\text { Contrast delivery }\end{array}$ & $\begin{array}{l}\text { Balloon inflation } \\
\text { and stent delivery }\end{array}$ & $\begin{array}{l}\text { Cardiac arrest } \\
\text { Pericardial } \\
\text { effusion/tamponade } \\
\text { Life threatening bleed }\end{array}$ \\
\hline CRT & $\begin{array}{l}\text { Vascular access } \\
\text { Wound closure }\end{array}$ & $\begin{array}{l}\text { RV/RA lead placement } \\
\text { Access to coronary } \\
\text { sinus }\end{array}$ & $\begin{array}{l}\text { Placement of LV } \\
\text { lead/removal of } \\
\text { delivery sheath }\end{array}$ & $\begin{array}{l}\text { Cardiac arrest } \\
\text { Pericardial } \\
\text { effusion/tamponade } \\
\text { Life threatening bleed }\end{array}$ \\
\hline EPS/Ablation & Vascular access & $\begin{array}{l}\text { Catheter placement } \\
\text { Catheter exchange }\end{array}$ & $\begin{array}{l}\text { Ablation catheter } \\
\text { Signal analysis } \\
\text { Transeptal } \\
\text { puncture }\end{array}$ & $\begin{array}{l}\text { Cardiac arrest } \\
\text { Pericardial } \\
\text { effusion/tamponade } \\
\text { Life threatening bleed }\end{array}$ \\
\hline $\begin{array}{l}\text { Diagnostic } \\
\text { angiogram }\end{array}$ & Vascular access & $\begin{array}{l}\text { Catheter exchange } \\
\text { Contrast delivery }\end{array}$ & & $\begin{array}{l}\text { Cardiac arrest } \\
\text { Pericardial } \\
\text { effusion/tamponade } \\
\text { Life threatening bleed }\end{array}$ \\
\hline $\begin{array}{l}\text { Bradycardic } \\
\text { PPM or ICD }\end{array}$ & $\begin{array}{l}\text { Vascular access } \\
\text { Wound closure }\end{array}$ & RV/RA lead placement & & $\begin{array}{l}\text { Cardiac arrest } \\
\text { Pericardial } \\
\text { effusion/tamponade } \\
\text { Life threatening bleed }\end{array}$ \\
\hline $\begin{array}{l}\text { PPM Box } \\
\text { change }\end{array}$ & Wound closure & & & Cardiac arrest \\
\hline
\end{tabular}


non-emergent interruptions and disturbances, in an attempt to improve operator conditions and overall patient safety.

Conflict of Interest Nil

\section{INVASIVE CORONARY PHYSIOLOGY BEFORE AND AFTER TAVI: A QUANTITATIVE META-ANALYSIS}

${ }^{1}$ Rafail Kotronias*, ${ }^{2}$ Roberto Scarsini, ${ }^{3}$ Skanda Rajasundaram, ${ }^{4}$ Giovanni Luigi De Maria, ${ }^{5}$ Flavio Ribichini, ${ }^{6}$ Rajesh Kharbanda, ${ }^{7}$ Adrian Banning. ${ }^{1}$ Heart Centre, Oxford University Hospitals NHS Trust; ${ }^{2}$ Heart Centre, Oxford University Hospitals NHS Trust; ${ }^{3}$ Heart Centre, Oxford University Hospitals NHS Trust; ${ }^{4}$ Heart Centre, Oxford University Hospitals NHS Trust; ${ }^{5}$ Division of Cardiology, University of Verona; ${ }^{6}$ NIHR University of Oxford BRC and Oxford University Hospitals NHS Foundation Trust; ${ }^{7}$ Heart Centre, Oxford University Hospitals NHS Trust

\subsection{6/heartjnl-2019-BCS.53}

Introduction As TAVI expands to younger and lower surgical risk severe AS patients, appropriately treating co-existent coronary artery disease is key to improving long-term cardiovascular outcomes. Recently, coronary physiology has been studied in patients undergoing TAVI in an attempt to incorporate it in revascularisation strategies. We seek to perform a meta-analysis of studies exploring the influence of TAVI on coronary physiology.

Methods We conducted a search of Medline and EMBASE to identify studies evaluating coronary physiology indices before and after TAVI. Double independent screenings and extractions were employed. Random effect meta-analysis with the inverse variance methods were used to estimate the pooled mean difference of coronary haemodynamic indices before and after TAVI. Analyses were performed with RevMan (Review Manager version 5.3.5, Nordic Cochrane Centre, Denmark).

Results Five studies evaluating coronary physiology in169 severe AS patients with 250 interrogated coronaries were included in the quantitative meta-analysis. The mean participant age and aortic valve area were 81 and $0.71 \mathrm{~cm}^{2}$ respectively. In non-diseased coronary vessels, coronary flow reserve (CFR) and fractional flow reserve (FFR) did not significantly differ following TAVR; mean difference 0.11 ; 95\% CI -0.10 , $0.32 ; \mathrm{p}=0.29 ; \mathrm{I} 2=0 \% ; \mathrm{p}=0.68 ; \mathrm{n}=3$ and mean difference $0.01 ; 95 \%$ CI $-0.04,0.03 ; \mathrm{p}=0.75, \mathrm{I} 2=41 ; \mathrm{p}=0.19 ; \mathrm{n}=2$ respectively. In stenosed vessels, FFR and instantaneous wavefree ratio (iFR) did not significantly change following TAVR with comparable precision; mean difference -0.01 ; $95 \%$ CI $0.03,0.01 ; \mathrm{p}=0.49, \mathrm{I} 2=0 \% ; \mathrm{p}=0.46 ; \mathrm{n}=3$ and mean difference $0.00 ; 95 \%$ CI $-0.02,0.02 ; \mathrm{p}=1.00, \mathrm{I} 2=0 ; \mathrm{p}=1.00 ; \mathrm{n}=2$ respectively.

Conclusion Our meta-analysis demonstrates that there are only minor, non-significant variations in coronary physiology measurements of severe AS patients before and after TAVI. The stability of invasive physiology assessment in severe AS patients is important for its incorporation in decision making algorithms. Studies investigating optimal ischaemic and intervention FFR and iFR cut-offs in patients with severe AS are anticipated.

Conflict of Interest None

\section{PREDICTING POOR SHORT AND MEDIUM-TERM SURVIVAL AFTER TAVI: A SINGLE UK CENTRE EXPERIENCE}

${ }^{1}$ Lee Zong Xuan*, ${ }^{2}$ Elangovan Senthil, ${ }^{2}$ Anderson Richard, ${ }^{3}$ Groves Peter. ${ }^{1}$ Cardiff University School of Medicine; ${ }^{2}$ Cardiff and Vale UHB; ${ }^{3}$ University Hospital Wales

\subsection{6/heartjnl-2019-BCS.54}

Transcatheter Aortic Valve Implantation (TAVI) for severe, symptomatic aortic stenosis improves quality of life and survival in most patients. It is, however, important to identify patients who are unlikely to get these benefits from TAVI so that futile treatment can be avoided. Futility in this context can be regarded as lack of functional improvement or death within the first two years after the procedure. The FRANCE-2 multi-parametric risk score was previously developed to predict mortality after TAVI and comprises 9 pre-procedural factors integrated into a 21-point scoring system. The FRANCE2 score was originally validated against early (up to 30 days) mortality after TAVI but its value in anticipating longer term outcomes is uncertain. The aims of this study were to determine whether the FRANCE-2 scoring system is of value in determining medium as well as short term survival in patients undergoing TAVI in a single UK centre and to compare its relative merits in this regard with the logistic EuroSCORE. A cohort of 187 consecutive patients undergoing TAVI in a single UK centre were studied. Baseline clinical data were collected from the UK Central Cardiac Audit Database (CCAD) and patient records. Mortality tracking was achieved in 100\% of patients. FRANCE-2 risk scores were calculated retrospectively and c-statistics were applied to determine the discriminative power of the FRANCE-2 score and the logistic EuroSCORE in associating with mortality. Using the FRANCE2 scores, the patients were divided into low risk (score 0 ), moderate risk (score 1-5) and high risk (score >5) groups and the survival outcomes were compared. Of the 187 patients, $57.2 \%$ were male and the mean age was $80.9 \pm 6.9$ years. Survival rates after TAVI at 30-days, 1 - and 2-years were $95.7 \% \quad(n=179), 88.2 \% \quad(n=165)$ and $77.5 \% \quad(n=145)$ respectively. The frequency of high risk parameters in this cohort of patients that contributed to the FRANCE-2 scores is shown in the table. The median score was 2 and the highest

\begin{tabular}{|c|c|}
\hline Patient parameters contributing to FRANCE-2 score & Values \\
\hline Age $\geq 90$ years & $7.0 \%(n=13)$ \\
\hline $\mathrm{BMI}<18.5$ & $1.6 \%(n=3)$ \\
\hline New York Heart Association Class IV & $7.5 \%(n=14)$ \\
\hline Acute pulmonary oedema $\geq 2$ in past year & $6.4 \%(n=12)$ \\
\hline Systolic pulmonary artery pressure $\geq 60 \mathrm{mmHg}$ & $5.9 \%(n=11)$ \\
\hline Critical pre-operative state & $4.3 \%(n=8)$ \\
\hline Respiratory insufficiency & $43.9 \%(n=82)$ \\
\hline Dialysis & $1.1 \%(n=2)$ \\
\hline Transfemoral approach & $93 \%(n=174)$ \\
\hline
\end{tabular}

